\title{
Awareness of Digital Footprint Management in the New Media Amongst Youth
}

\author{
TENGKU SITI MERIAM TENGKU WOOK \\ HAZURA MOHAMED \\ SITI FADZILAH MAT NOOR \\ ZURINA MUDA \\ INTAN YUSRINA ZAIRON \\ Universiti Kebangsaan Malaysia
}

\begin{abstract}
The industrial revolution creates a new era where everything can be accessed via the Internet. However, despite all the advantages, the new era of technology comes with disadvantages as well. Studies have shown that the youth category is the group that is a synonym to technology. Most of the youth nowadays enjoy using the features but lacked the information on the footprint of their Internet browsing history. When individuals engaged with the Internet, they generated a complex trail of these digital footprints that may include their various presentation of self, based on social profiles and comments, traces of their activities, interest, interaction and anything else they choose to share online. However, the extent to which netizens are aware that they are creating these tracks and traces and have some ability to manipulate and control them is unclear at present. Thus, the objective of this paper is to identify the level of awareness among youth about the digital footprint. The research started with a structured survey distributed to respondents as a data collection requirement for analysis. A quantitative research method is employed in this research. Survey was conducted to the three main areas namely urban, suburban and rural as a sample of the population. Results were presented in the form of description analysis with respondents demographic and perception of respondents based on digital footprint awareness.
\end{abstract}

Keywords: Industrial revolution, digital, footprint, awareness, youth, technology.

\section{INTRODUCTION}

The development of information and communication technology creates various issues and engaging discussion in the new media that may guide people towards understanding of Islam. The existence of new media has greatly changed the pattern of youth social life, especially to Muslim youth (netizens). The emergence of the Internet as a medium of communication has provided many benefits to the user but at the same time, new media also bring a variety threats such as sedition threats, defamation, pornography and others (Wan Amizah \& Muhammad Adnan, 2017). One example of new media includes social media. Social media is a social interaction between individuals in virtual communities and network where they generate and share data and thoughts. The function of the crowd as a consumer who is actively involved in the content is an important element of social media. Social networking such as Facebook and LinkedIn, media sharing platform as YouTube, Flickr and Instagram, Twitter as microblogging and blogs are all examples of social media. 
Today, the usage of digital technologies such as mobile phones and laptop computers make it easier and frequent for consumers to access social media easily and substantially increased the uptake of social media. Thus, people are giving out more personal information about themselves online than ever before such as sharing their locations, contact information, credit card numbers on sites of media social (Czodli, 2016) which are referred as a digital footprint. Digital footprint relates to the information and data that individuals produce when they go online through purposeful action or passive recording (Thatcher, 2014). The use of digitized footprints as a means of identity verification and the suitability of applicants for roles within an organization is growing among applicants to universities and employers. The digital footprints left by the use of the Internet and social media may possibly influence their future careers or opportunities for employment. Media accounts are increasingly describing cases of people losing their employment or being discount on their social media accounts from higher education programmes. This happens because Internet users are not aware of the hidden agenda behind their computers and the data or information they shared. Additionally, it also provides manipulative and interactive features that could influence youngsters in term of purchasing things, playing computer games and reading or watching various digital materials available on sites. One way that digital footprint is left behind according to the Internet Society are through retailers who left cookies in a user system to track the user's activities (Czodli, 2016).

This is because they can put advertisements on user browsers for products that they have recently looked-up or may be interested in based on user online history. The new media also has begun and caused a group of netizens to feel gratitude towards the western world that promotes human rights and freedoms of life. They assume that the use of new media can effectively enhance social, economic and cultural, besides being able to share the information easily. However, unknowingly users actually left footprints on the visited websites which is called digital footprint. The effect of the digital footprint can be manipulated or channeled to third parties for profit and exploitation purposes. It cannot be easily deleted because all information has been shared online. The media often portray the Internet as a technology that has corrupted young lives, concentrating on tales about kids addicted to the Internet, paedophiles stalking kids online, cyberbullying destroying the lives of young people and dangerous sexual behaviours of teenagers other than victims of cyberbullying, product purchase frauds, depression in social networks, sexual harassment, and inappropriate content disclosure. Besides, digital footprint also can be considered as passive participation from netizens through the content of production and sharing towards social media (Buchanan et al., 2017).

Based on the advancement of global technology, social media can be categorized under the development of the Internet of Things (IOT). IOT is the latest trend revealing a webbased architecture of the next generation, to facilitate data flows through the supply chain network. loT acted as one of nine milestones for the challenges of the $4^{\text {th }}$ industrial revolution. Revolution 4.0 was triggered by the majority of Asian countries in order to apply and assist the country's annual growth rate. Revolution 4.0 based on loT or better known as Multi-Purpose Internet is a combination of machines and the web in generating systems for the entire production chains. It is a network of real objects - devices, wearable, cars, etc. with sensors, software, and network connectivity that enable information collection and exchange between 
objects through the web or wireless communication technologies. It has the ability to incorporate people's everyday activities into the Internet, which will lead to many advanced technological capacities in the future. This channel creates new possibilities and challenges towards this new era. Thus, the advantage of loT has created a channel for citizens to access information via the Internet. Sharon (2011) found that people prefer alternative news websites because they believe that the sources are more accurate and thus more trustworthy. Contradictory to Bambang (2019), readers are taught things that are not true and inappropriate by the media. However, every advantage will come together with a disadvantage.

The achievement of social media is useful to optimize interactions between objects and the use of social networking values in the loT. The ubiquity of social media has led to comprehensive apps with a growing amount of businesses incorporating social media in their organisation. According to Bughin et al. (2011) from McKinsey Global Institute study of how organisations use Social Media, businesses enhance their social media proficiently, use them to enhance activities and take advantage of fresh market possibilities. Social network acts as a good platform as a matter of fact which afford many simple user actions, such as liking, favoriting, following, or commenting which are not necessarily considered active participation but nonetheless contribute to a digital footprint (Büchi, Lutz \& Micheli, 2017). Although young individuals are often online, they do not consider deliberately how their Internet usage impacts their digital identity, instead, concentrating more on the short-term advantages of being able to network with friends (Oxley, 2010). One of the most common Internet use is communicating with others through social networking platform. This leads to an individual's Internet identity and creation of a person's digital footprint which is traceable data and information that a user generates when they go online (Thatcher, 2014).

Therefore, this study takes an initiative to analyse the awareness level of digital footprint management in new media among Muslim youths in Malaysia. The survey method is conducted through a questionnaire on 234 netizens users as a random sample throughout Malaysia covering urban, rural and suburban areas.

\section{DIGITAL FOOTPRINT MANAGEMENT}

According to the domain of footprint purpose, this topic can be categorized into two sections. The first section is the youth and technologies and the second section is the digital footprint.

\section{a. Youth and Technology}

Comparatively, youth and technology are two subjects that are synonym in new media issues nowadays, in which both are equally important categories. Despite all the advantages, there are still some bad impacts on the new era of technology. Everything can be accessed easily via the Internet without boundaries. Although it is true that the Internet plays a major role for daily activities, the impact of the Internet could also cause destruction as much as the advantage. In the past few decades, youth was the subject that most easily adaptable to the impact of the technology enhancement with changes that occurred with it (Camacho et al., 2012). By the same token, youth as stated by Hargrove et al. (2014) is focused more on social age and not a developmental period which is the transition period between the dependency of 
childhood and responsibility of adulthood. Hence, youth is also considered as a vulnerable age. In the aspect of technology, this will affect their growth as well as the environment where the exposure of technology in terms of Internet and social media. In other words, youth will be exposed to unhealthy activities within the Internet and social media which can lead to emotional instability. To point out, Richards et al. (2015), identified that the health impact on social media on youth was among the greatest on mental health with the related issues around cyberbullying and 'Facebook depression'.

Generally, new media could be presented as a comprehensive introduction to the culture, history, technologies, and theories of new media (Lister et al., 2009). New media in most of the netizens' daily lives are mainly affected by the approach of cyberculture, technology, nature, and culture. The platform of new media provides the intensity of change with the emersion of sense to capture the world of media, and communication was not restricted to any sector or element of the world. According to Lister et al. (2009), new media are associated with the following kinds of social, economic and cultural change:

i. A shift from modernity to post modernity

ii. Intensifying process of globalization

iii. A replacement in the west of an industrial age of manufacturing by a 'post-industrial' information age.

iv. A decentring of established and centralised geopolitical orders

Recently, the impact of this new media technology is radically transforming the world which affects culture, society and politics. Thus, the impact of new media on a Muslim's contemporary society shows more significant than global new media significance (Shuriye et al., 2013). This modernization of new media imposes a critical perspective towards Islam which has become a critical perspective in the world. The term 'Islam' refers to a religion that finds diverse cultural expression around the world (Shuriye et al., 2013). The emergence of modern communication technology has made the new media the most important and immediate influence on opinion and understanding in the world. However, most Muslim netizens benefit new media as a platform for the youth to be involved with the new culture of media.

The power of new media in technology encourage the global awareness and thus market the cross-cultural understanding, tolerance, ethics acceptance, religious, gender and many more towards the unifying the communities across the globe. As we know new media played as a major role in new globalization era and able to attract in each single age and dimension of netizen. In addition, new media also provide the advancement in the aspect of information and communication. Thus, this affected netizens in the aspect of their attitude, social and culture (Sohana, 2016). There are few factors that caused the Islam's youth involve with the new media without boundary for example social economic. This is because the influence of socio economic begin in the prenatal environment and continue through life as they can result in economic hardship, lacked of social support, low educational level and selfesteem and lead to the use of new media. But, the introduction of new media results the netizens share their negative thing that bring them to social ill towards youth of Islam. However, Saodah, Syed Arabi and Ealyna (2012), saying the relevance behind new media is the youngsters whom the one shall ruling and shaping the landscape of the country in the future on all aspects especially in political, social and economic. Regarding religious content, Iswandi 
(2018) considered religion should not be learnt and contemplated via social media as that are deemed inadequate to provide elaborations on various religious issues.

Thus, the new media browsing and social media sharing provide the digital footprint towards all the activities history which acts as the main purpose of awareness in this project. In order to create a respectable youth in the future, knowledge and exposure towards the awareness of negativity of digital footprint should be taken into action. The impact of digital footprint might affect not only for now, but also might cause a bigger impact in the future around the world. The impact of digital footprint should bring the user towards the positive action rather than negative action as we can see today.

\section{b. Digital Footprint}

Similarly, to youth and technology, digital footprint is barely able to help to track the social connection either to individuals or groups that evolve within the real environment. In the same fashion, social medias such as Twitter and Facebook was used to measure the density of crowd and social in order to help identify the connection towards the user. Individuals and crowd have high possibilities of forming communities in the presence of specific events such as alarm or disaster scenario (Espinosa-Oviedo et al., 2017). In addition to that, mostly netizens use social networks as new media to document their lives effectively (Büchi, Lutz \& Micheli, 2017). However, this may cause more harm rather than good. For example, cyber bullying. Englander et al. (2017) conclude cyber bullying as sending, posting or sharing negative, harmful, false or mean content about someone else causing embarrassment or humiliation online. As to avoid that, it is important to educate people not only to kids, but also includes all categories especially parents. This leads to awareness of digital citizenship to give attention towards the improper behaviour that may lead to dangers of cyber bullying and other social-media events (Martin et al., 2018).

Thus, the new media browsing and social media sharing provide the digital footprint towards all the activities history which acts as the main purpose of awareness in this project. In order to create a respectable youth in the future, knowledge and exposure towards the awareness of negativity of digital footprint should be taken into action. The impact of digital footprint might affect not only for now but also might cause a bigger impact in the future around the world. The impact of digital footprint should bring the user towards the positive action and not negative action as we can see today.

\section{c. Digital Footprint}

Similarly, to youth and technology, a digital footprint is barely able to help to track the social connection either to individuals or groups that evolve within the real environment. In the same fashion, social media such as Twitter and Facebook was used to measure the density of crowd and social to help identify the connection towards the user. Individuals and crowd have high possibilities of forming communities in the presence of specific events such as alarm or disaster scenario (Espinosa-Oviedo et al., 2017). In addition to that, mostly netizens use social networks as new media to document their lives effectively (Büchi, Lutz \& Micheli, 2017). However, this may cause more harm and not good. For example, cyberbullying. Englander et al. (2017) conclude cyberbullying as sending, posting or sharing negative, harmful, false or mean content 
about someone else causing embarrassment or humiliation online. As to avoid that, it is important to educate people not only to kids but also includes all categories especially parents. This leads to awareness of digital citizenship to give attention to the improper behaviour that may lead to dangers of cyberbullying and other social-media events (Martin et al., 2018).

The issues of youth, technology and digital footprint are considered as challenges for the 4th industrial revolution. Besides, the education of awareness has been discussed in the platform of education challenges towards youth nowadays. In the era of $4^{\text {th }}$ revolution, new media technology has resulted in great social change to netizens to portray behaviours and lifestyles by affecting the way they behave, communicate, learn and plan about themselves and their surroundings (Hajli, 2014). However, a stern alarm should be given to them in order to notify about the disadvantages. Netizens need to be exposed and educated in the right way about the potential dangers of using new media because their lives are being recorded. There are many negative elements in the digital footprint when information sharing takes place, among other things, it is a shame when netizens send information and talk about the harm of others, bullying in cyberspace, sex conversations or product purchase fraud. The negative thing will spread widely and quickly and it cannot be removed because it has been shared by others in the network (Fani, 2015). Digital footprint is important to be understood and taught, especially to produce and create something online and netizens should be aware that what they produce on the Internet is permanent.

Therefore, digital footprint can cause the risks in terms of reputation and safety. In aspect of reputation, it may harm for education and career. Besides, in terms of safety, digital footprint will increase the chances of being tracked, stalked and harassed. The topic of digital footprint gaps is complex as it involves various actors, from individual users and their network, to platform providers, data brokers, civil rights groups, and government institutions (Büchi, Lutz \& Micheli, 2017). Good online behaviour should be practiced in all aspects of their digital world, whether education, personal or professional. One of the practise for good online behaviour is by curation. The notion of curation in relation to the online identity and exercise of people is gaining traction. Given the effect of the Internet on jobs and work, healing is a significant skill for young individuals to manage their digital footprints over the long term. Curation is a "key competence" for critical research, Internet presence and digital culture involvement. Instead of being alert to the consequences a negative one can have, children and adolescents should be educated to cure a favourable digital footprint. If netizens can see how their online interactions can have an impact in the future, they can have a better understand on how to behave in the digital world (Lambiotte \& Kosinski, 2014). Figure 1 shows the illustration and definition of digital footprint: 


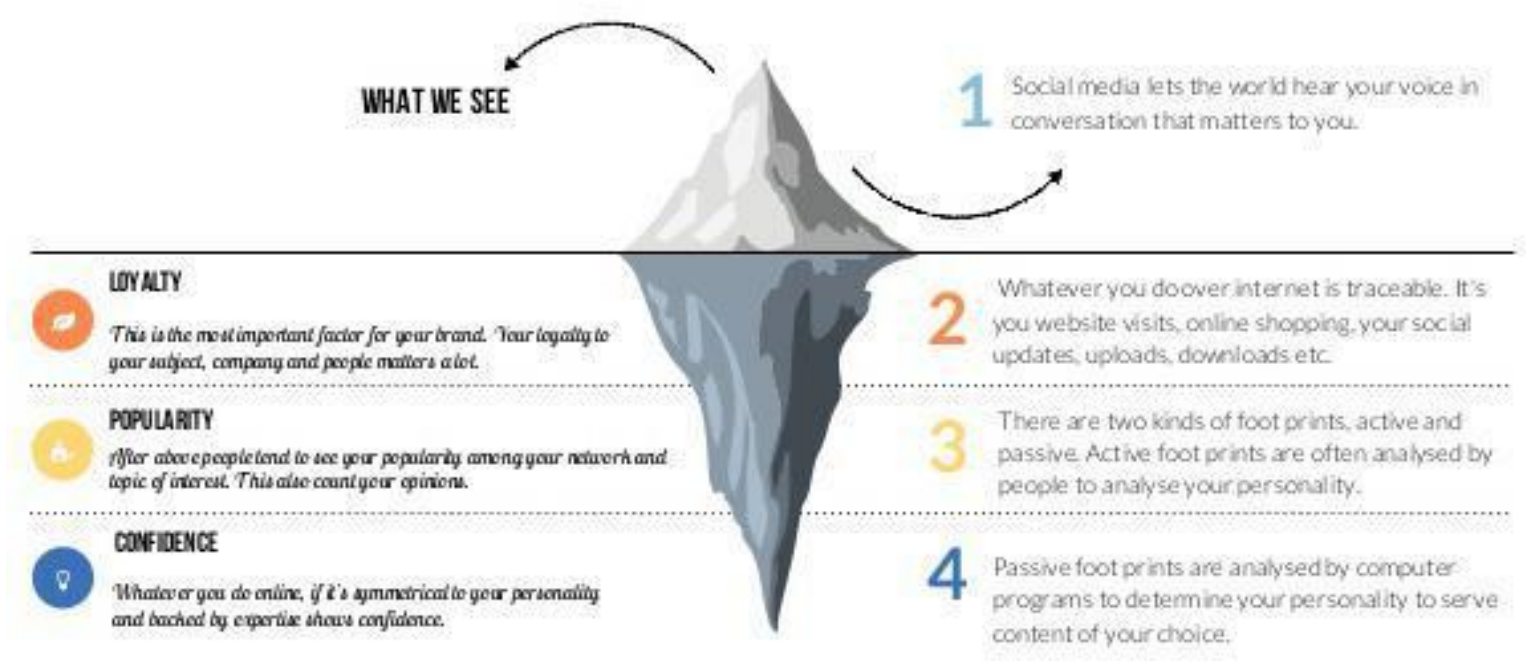

Figure 1: Illustration of Digital Footprint Definition (Source: Amit Mishra, 2017)

There are two types of digital footprint which are passive and active digital footprint (McDermot, 2018). A passive digital footprint is a data trail or information path which user inadvertently leave online. For instance, when the user visit a website, IP address may be logged on to the webserver, which then identifies Internet service provider and user approximate location. Although the IP address may change and does not include any personal data, it still remains part of users' digital footprint. Search history, which is saved by some search engines when user logs in is a more private element of the passive digital footprint. Meanwhile, an active digital footprint involves information that user submit online deliberately. Example one of the activities that contribute to an active digital footprint is sending an email, as user expect other individuals to view and/or save information. The more email sent, the more digital footprint grows. Since most people save their email online, the emails can readily stay online for several years or longer. Individuals who are not trained on digital footprints and do not have the required knowledge or abilities to depict a favourable Internet presence may have a potential disadvantage.

Some teenagers learn from their parents about technology while others teach their parents how to perform a search query or complete a job application. There is a solid connection between social disadvantage and digital disengagement. While access to the Internet and technology has improved for socially disadvantaged communities, online social spaces function in a comparable way to everyday spaces; meaning that some organizations have more desirable types of digital social capital. Communicating with others through social networking services is one of the Internet's most common uses.

\section{METHODOLOGY}

This study has been conducted to analyse netizens profiles while using Internet. The objective of this study is to identify the level of understanding and awareness of the digital footprint in new media. 


\section{a. Instruments}

In order to obtain an accurate result of the survey based on respondents, the Cronbach's alpha test was conducted first towards 26 respondents. The surveyed was expressed as a number between 0 to 1 which explain the internal consistency before the real test to ensure the validity (Javakol \& Dennick, 2011). However, there are different reports about the acceptable value of alpha ranging from 0.70 to 0.95 . Reliability of the test presents the measurement error in a test and the correlation of test with itself. Thus, based on SPSS result, Cronbach's alpha for the survey is 0.61 indicate poor internal consistency of Cronbach's alpha. A poor of Cronbach's alpha could be due to a low number of questions, poor interrelated between items or heterogeneous constructs. (Javakol \& Dennick, 2011). Below are the Table 1 selection of coefficient Cronbach's alpha.

Table 1: Selection of cronbach's alpha value

\begin{tabular}{cc}
\hline Cronbach's Alpha & Std Deviation \\
$\alpha=0.9$ & Excellent \\
$\alpha<0.9$ & Good \\
$\alpha<0.7$ & Acceptable \\
$\alpha<0.6$ & Poor \\
$\alpha<0.5$ & Unacceptable \\
\hline
\end{tabular}

However, poor Cronbach's alpha usually due to poor connection between items and some of the data has been revised or discarded. Cronbach's alpha can be viewed as a measure of flow for the total sum score on selected items that capture by selected score in the entire domain. Most of the case, the alpha value approaching to zero was deleted due to question with low correlation and incomplete answer by respondents. A maximum of alpha value of 0.61 is obtained for which is acceptable. According to Table 1 where value $\alpha=0.61<0.7$ indicated as acceptable value for internal consistency (Manerikar \& Manerikar, 2015). Thus, with that validation, the survey is proceeding with 234 respondents to estimate the awareness prevalence within the area of study. Survey was distributed to respondents via online Google forms. The questionnaire was constructed based on the following categories:

i. Identifying the demographic information about the respondents and general information about their knowledge pertaining to digital footprint.

ii. Respondent's level of awareness concludes to four main points:

- Respondent have knowledge of digital footprint

- $\quad$ Respondent does not aware and does not expecting risk

- Respondent do not care about the risk

- Respondent does not aware of their action might cause risk

The survey feedback categorized the level of respondent's awareness according to the Likert scale ranging from 1 (extremely disagree) to 5 (extremely agree). The answers may vary due to the experience and environment of a particular respondent. 


\section{b. Sample}

Survey has been conducted to 234 respondents in order to obtain the feedback of digital footprint awareness. The analysis is based on the collected data of digital footprint awareness survey among Malaysia youths within the age of 15-30 years old.

\section{RESULTS}

Response received from 234 respondents is compiled and analysed to study the netizens' awareness towards digital footprint. The netizens profiles are divided into five main factors which include the active user of the Internet, age, perception, socio-economic and Internet surfing. Figure 2 shows the percentage of respondents that participate in the survey. As the requirement of youth age is between 15-30 years old, the percentage obtained are in equal balance ratio for three categories of youth age. From the result, a total of 70 responders are from age 15-20 category, 75 responders are from 21-25 years old and the remaining 89 responders are from age $26-30$ categories.

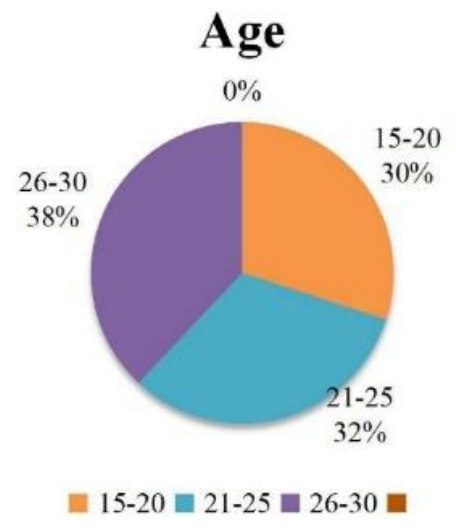

Figure 2: The Percentage of respondent's age

Based on the age range percentage that includes Internet surfing factor, about $99 \%$ of the respondents use new media in their life and can be considered as active Internet users. Thus, these proved that youth is the major category that should be focussed to create awareness on the digital footprint. Other than that, three-section from questionnaires can lead to perception result that has been affected by the socio-economic category. This result can be derived by netizens' area factor. The result of the area factor is as shown in Figure 3. 


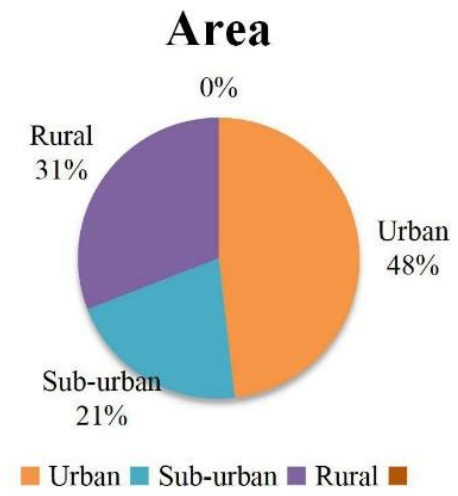

Figure 3: Percentage of area

Figure 3 shows the total respondents from the urban area are 112 people resulting in $48 \%, 73$ people or $31 \%$ are from the rural area and lastly, 49 people or $21 \%$ of total respondents initially from the sub-urban area which considered as netizens socio-economic. This shows that this survey has roughly covered by all areas. The environment and surrounding rural area nowadays are equipped with Internet coverage. Therefore, active users could be from a rural area as well. Active and Internet surfing plays an equally important factor for the awareness of digital footprint. Active user of the Internet will explore tremendously more as compared to non-active user. As a result, these two factors will be linked to the perception as stated in Table 2 of the analysis. In general, active and Internet surfing factor create a final analysis for other factors as well.

Next, the result of analysis towards 234 respondents brings to 4 possibilities of perceptions as presented in Table 2. Perceptions acts as an action that reacts by netizens once the survey was done. The result of the mean score for each perception category and overall constructed in Table 2 below:

Table 2: Perception of digital footprint awareness

\begin{tabular}{lcc}
\hline \multicolumn{1}{c}{ Perception } & N & Mean \\
\hline $\begin{array}{l}\text { Respondents have knowledge of digital } \\
\text { footprint }\end{array}$ & 234 & 1.75 \\
$\begin{array}{l}\text { Respondents does not aware and does } \\
\text { not expecting risk }\end{array}$ & 234 & 3.89 \\
$\begin{array}{l}\text { Respondents do not care about the risk } \\
\text { Respondent does not aware of their }\end{array}$ & 234 & 3.45 \\
action may cause risk & 234 & 3.92 \\
All question & 234 & 2.86 \\
Conclusion & 234 & 1.98 \\
\hline
\end{tabular}

The mean scores are grouped into three categories namely, less awareness (1-2.33), moderate awareness (2.34-3.67) and high awareness (3.68-5.00). 
Table 3: Awareness level value

\begin{tabular}{cc}
\hline Level Value & Awareness Level \\
\hline Low $(1-2.33)$ & Aware and alert \\
Moderate $(2.34-3.67)$ & Less aware \\
High $(3.68-5.00)$ & Unaware \\
\hline
\end{tabular}

Based on Table 2 above, perception 1 towards 234 netizens creates the mean=1.75 which indicate netizens have less awareness towards the knowledge of digital footprint. As the awareness levels are contradicting and to the value of the mean, these are proved that netizens are less aware of the digital footprint. Next, followed by perception 2 which indicate the respondents do not aware and does not expecting the risk result mean $=3.89$. This shows that it is true that netizens agreed with perception 2 . The main reason behind this result might due to perception of an individual. Some might act as they know but not expecting to happen to them. Moving to perception 3, where respondents do not care about the risk create the amount of mean $=3.45$. Again, this proved that netizens agreed with the perception that has been presented which negatively contradict to the value of mean. Lastly, perception 4 provide mean $=3.92$ which proved that the perspective agreed by netizens by area towards the awareness of digital footprint very low.

\section{DISCUSSION}

The result analysis also shows that about $99 \%$ of respondents are considered as active Internet users which contribute to the percentage of Internet surfing factor. Thus, these proved that youth is the major category that should be focused on to have media literacy awareness of digital footprint. In other words, Internet surfing factor is equally important as other factors that contribute to the result. Active users have a high tendency to explore information on social media, as compared to a passive user. Hence, the active Internet user may explore anything they would like to know including the aspect of security. However, the possibility for active users to ignore or skip the important information of awareness might happen. According to usability experts, there are four main influences which are age, education, culture, and industry.

Mainly, the active Internet user is in young age that tends to click more and read less compared to older users who are reading and processing more slower but often more thoroughly. Education also correlates with reading levels as low-literacy readers will skip over text or click any link to avoid reading. Other than that, culture also plays the main factor because it is a mixture of customs, beliefs and societal expectations. So, together these things shape users' worldview and can have a powerful influence on user compliance. Lastly, this action also has been influenced by the industry where the user works. Users are more likely to be well-trained in processes in heavily regulated industries. So, compared to users from more free-wheeling industries, they tend to be more used to reading and following instructions.

This can be seen from the perception result of the netizens that was affected by the socio-economic category based on the three sections of the questionnaires. Each variable depends on the individual, thus it presents the result of the survey. In addition to that, education also plays a key role in influencing other factors. People with good education 
background contribute with high percentage, compared to people without education background that also depends on the area of s live. In this survey, the area factor can be divided into three categories: a) urban; b) sub-urban; and c) rural. Even though there is an individual who stays in rural areas with lack of education background, but he may have the awareness and knowledge about the digital footprint.

Apart from that, the educational levels category also included in the survey to identify awareness. The educational levels are accessed in general without considering the area where an individual comes from. This indicates that awareness is not limited to the urban area only. Thus it also brings to social status based on their academic achievement. Social status gives a rank to an individual indirectly. Individuals in greater socioeconomic status [SES] households are more likely to receive help in improving their knowledge and use of the Internet, as they have more regular access to it, as well as others who can help them (Dolan, 2016). Digital literacy and computer abilities are increasingly being appreciated; those with low SES are therefore at a disadvantage. Individual who are not trained on digital footprints and do not have the required knowledge or abilities to depict a favourable Internet presence may have a disadvantage. However, not all people with high social status are aware of the digital footprint awareness and consequently affect their title in the educational background towards the awareness of digital footprint. The result may be varied and caused by types of job and the environment surrounded by the area they live in.

Overall, the respondents have agreed that they have less awareness pertaining to digital footprint according to Table 3. To sum up, the open-ended questions feedback from the respondents via the questionnaire creates the statements below:

i. Information shared and uploaded via online has risks

ii. We should be responsible for all the information being uploaded and downloaded on the Internet

iii. The respondent will look for information about themselves on the Internet to ensure the information displayed or save are true and genuine.

iv. The respondent should often use privacy mode when surfing the Internet to avoid their activities from being tracked.

v. Respondent should be aware of the existence of privacy mode in the search engine to surf the Internet.

vi. Respondent will log out from social media when using a computer that does not belong to them.

The analysis shows that overall users are aware of the bad impact of Internet usage and are alert with the consequences. However, there are some points that the users are still unaware of the security purpose of Internet use in social media. Plus, most of the percentage in the results and findings show that the users are aware of the world of digital footprint.

\section{CONCLUSION}

To conclude, the age of social media nowadays comes with more challenges rather than the advantage of new era technologies. Exposure towards social media definitely will create the digital footprint based on netizens activities and they be should aware of the risk. The survey result in this project proved that most netizens are aware of the bad impact towards digital 
footprint but they also still unaware of the impact of security purpose of Internet usage. As we can see, the total question of survey record the mean $=2.86$ indicate most of the netizens still less aware of digital footprint. Besides, other factors such as socio-economic also act as a major key to the exposure of youth and technologies nowadays. Various socio-economic creates a different pattern of engagement from netizens towards the framework of digital footprint of social media. A digital footprint can be considered based on how online traces and their consequences vary according to socio-demographic variables and traditional markers of inequalities (Büchi, Lutz \& Micheli, 2017). Technologies and youth are two different subjects with different elements that able to bring modernization in the future. However, both of this subject has to be shaped through a good process in order to define a better result of our mankind. Therefore, netizens should expose themselves towards the awareness of social media activities which indirectly create the digital footprint for unforeseen consequences in the future.

\section{ACKNOWLEDGEMENT}

This study is supported by research grant Cabaran Perdana - Islam Kontemporari, DCP-2017013/5 Universiti Kebangsaan Malaysia, Faculty of Information Science and Technology, Software and Management Technology Center and Multimedia Research Group.

\section{BIODATA}

Tengku Siti Meriam Tengku Wook is a senior lecturer at Faculty of Technology \& Information Science, National University of Malaysia, specialized in multimedia application, interaction design and usability and virtual \& agmented reality. Email: tsmeriam@ukm.edu.my

Hazura Mohamed is a senior lecturer at Faculty of Technology \& Information Science, National University of Malaysia, specialized in quality model. Email: hazura.mohamed@ukm.edu.my

Siti Fadzilah Mat Noor is a senior lecturer at Faculty of Technology \& Information Science, National University of Malaysia, specialized in multimedia application and e-learning technology. Email: fadzilah@ukm.edu.my

Zurina Muda is a senior lecturer at Faculty of Technology \& Information Science, National University of Malaysia, specialized in semantic image processing, multimedia interactive and intelligent application and spatial image annotation and retrieval. Email: zurinam@ukm.edu.my

Intan Yusrina Zairon is a research assistant at Faculty of Technology \& Information Science, National University of Malaysia. Email: intanyusrina@gmail.com 


\section{REFERENCES}

Bambang Sukma Wijaya. (2019). Dancing with the impropriety of media: How Indonesian consumers think and behave towards the unethical and illogical online news. Jurnal Komunikasi: Malaysian Journal of Communication, 35(1), 187-205. doi: 10.17576/jkmjc2019-3501-13

Buchanan, R., Southgate, E., Smith, S. P., Murray, T., \& Noble, B. (2017). Post no photos, leave no trace: Children's digital footprint management strategies. E-Learning and Digital Media, 14(5), 275-290. doi: 10.1177/2042753017751711

Büchi, M., Lutz, C., \& Micheli, M. (2017). Life online: The digital footprint gap. Digital Divide 2017 International Conference, (pp. 2-6). California.

Bughin J., Byers A. H., \& Chui, M. (November, 2011). How social technologies are extending the organization. Retrieved from https://www.mckinsey.com/industries/technology-mediaand-telecommunications/our-insights/how-social-technologies-are-extending-theorganization\#

Camacho, M., Minelli, J., \& Grosseck, G. (2012). Self and identity: Raising undergraduate students' awareness on their digital footprints. Procedia - Social and Behavioral Sciences, 46, 3176-3181. doi: 10.1016/j.sbspro.2012.06.032

Czodli, B. (2016). Privacy and security online: Protecting your digital footprint. Retrieved from http://www.users.miamioh.edu/viscokj/IMS201/website/chapter-04.html

Dennick, M. T. (2011). Making sense to cronsbach's alpha. International Journal of Medical Education, 2, 53-55.

Dolan, J. E. (2016). Splicing the divide: A review of research on the evolving digital divide among K-12 students. Journal of Research on Technology in Education, 48, 16-37. doi: 10.1080/15391523.2015.1103147

Englander, E., Donnerstein, E., Kowalski., R, Lin, C., \& Parti, K. (2017). Defining cyberbullying. Journal of the American Academy of Pediatrics, 140, S148-151.

Espinosa-Oviedo, J. A., Vargas-Solar, G., Alexandrov, V., \& Zechinelli-Martini, J. L. (2017). Correlating digital footprints for discovering social connections in crowds. IEEE2017 International Conference on Internet of Things (iThings) and IEEE Green Computing and Communications (GreenCom) and IEEE Cyber, Physical and Social Computing (CPSCom) and IEEE Smart Data (SmartData).

Fani, A. (2017, November 15). Harmful digital footprint impacts that parents should know about. Retrieved from www.fosi.org/good-digital-parenting/harmful-digital-footprintimpacts-teens/

Hajli, M. N. (2014). A study of the impact of social media on consumers. International Journal of Market Research, 56(3), 387-404.

Hamid, S. A. (2016). Pengaruh media massa terhadap perubahan sosial masyarakat. Journal of Social Science and Humanities, 1, 214-226.

Hargrove A., Pells K., Boyden J., \& Dornan P. (2014). Youth vulnerabilities in life course transitions. UNDP Human Development Reports. Retrieved from http://hdr.undp.org/en/content/youth-vulnerabilities-life-course-transitions

Iswandi Syahputra. (2018). New media, new relations: Cyberstalking on social media in the interaction of Muslim scholars and the public in West Sumatra, Indonesia. Jurnal Komunikasi: Malaysian Journal of Communication, 34(1), 153-169. 
Javakol M., \& Dennick, R. (2011), Making Sense of Cronbach's Alpha, International Journal of Medical Education, 2: 53-33

Konsinski, L. M. (2014). Tracking the digital footprints of personality. Proceeding of the IEEE 102 (12), 1934-1939

Lambiotte, R., \& Kosinski, M., (2014). Tracking the ditigal footprints of personality. Proceeding of the IEEE, 102(12), 1934-1939.

Lister, M., Dovey, J., Giddings, S., Grant, I., \& Kelly, K. (2009). New media: A critical introduction. London: Routledge.

Manerikar, V., \& Manerikar, S. (2015). Cronbach's alpha. A Peer Reviewed Research Journal aWEshkar, XIX (1), 117-119.

Martin, F., Wang, C., Petty, T., Wang, W., \& Wilkins, P. (2018). Middle school students' social media use. Journal of Educational Technology \& Society, 21(1), 213-224.

McDermot, M. (2018). Digital footprints: Creation, implication, and higher education. FDLA Journal, 3(11). Retrieved from https://nsuworks.nova.edu/fdla-journal/vol3/iss1/11/

Mishra, A. (2018, September 27). Digital persona: From learner to influencer. Retrieved from http://www.slideshare.net/amit_krm/digital-persona-from-learner-to-influencer

Mohd Yuszaidy Mohd Yusoff, \& Muammar Ghaddaffi Hanafiah. (2015). Impak media baharu terhadap sistem nilai masyarakat Melayu di Malaysia. Jurnal Komunikasi: Malaysian Journal of Communication, 31(2), 33-46.

Oxley, C. (2010). Digital citizenship: Developing an ethical and responsible online culture. Proceedings of the 12th Biennial School Library Association of Queensland.

Richards, D., Caldwell, P. H., \& Go, H. (2015). Impact of social media on the health of children and young people. Journal of Paediatrics and Child Health, 51(12), 1152-1157

Saodah Wok, Syed Arabi Idid, \& Ealyna Misman. (2012). Social media use for information Sharing activities among youth in Malaysia. Journalism and Mass Communication, 2(11), 1029-1047.

Sharma, B. (2016). A focus on reliability in development research through cronsbach's alpha among medical, dental and paramedical professionals. Asian Pacific Journal of Health Sciences, 3(4), 271-278.

Sharon Wilson, Pauline Leong, Carmen Nge, \& Ngerng Miang Hong. (2011). Trust and credibility of urban youth on online news media. Jurnal Komunikasi: Malaysian Journal of Communication, 27(2), 97-120.

Shuriye, A. O., Adeyemi, K., \& Huud, S. (2013) Impacts of new media technology on MuslimWestern relation. Journal of Asian Scientific Research, 3(12), 1210-1219

Sohana Abdul Hamid. (2016). Pengaruh media massa terhadap perubahan sosial masyarakat. Journal of Social Science and Humanities, 1, 214-226

Tavakol, M., \& Dennick, R. (2011). Making sense of cronbach's alpha. International Journal of Medical Education, 2, 53-33.

Thatcher, J. (2014) Living on fumes: Digital footprints, data fumes, and the limitations of spatial big data. International Journal of Communication, 8, 1765-1783.

Wan Amizah Wan Mahmud, \& Muhammad Adnan Pitchan. (2017). Media baharu dan institusi raja di Malaysia: Kes penghinaan raja-raja di media sosial. Jurnal Komunikasi: Malaysian Journal of Communication, 33(1), 406-422. 